\title{
Mito, narrativa e audiência no monólogo de Jocasta (Eur. Phoen. 1-87)
}

\author{
Evandro Luis Salvador \\ UNICAMP/ Departamento de Linguística \\ evandro_salvador@yahoo.com.br
}

Recibido: 12 de julio de 2010

Aceptado: 15 de diciembre de 2010

\begin{abstract}
RESUMEN
El artículo examina el monólogo (v.1-87) de Yocasta en el prólogo de la tragedia Las fenícias, de Eurípides, discutiendo la mirada de Yocasta sobre el mito de Lábdaco y cómo se recuperan elementos del monólogo ya conocidos por el público ateniense del siglo $\mathrm{V}$ a. $\mathrm{C}$, de forma que se crea y se mantiene en los espectadores un estado de tensión dramática.
\end{abstract}

Palabras clave: tragedia, Eurípides, Fenicias, Yocasta, mito, espectadores.

\begin{abstract}
This paper analyses the monologue of Jocasta (vv.1-87) on the prologue of Euripides' The Phoenician Women. I will discuss Jocasta's point of view about the myth of the Labdacids and how this monologue recovers some elements that are already known by the Athens audience from V B.C., which provokes and maintain a state of dramatic tension in that same audience.
\end{abstract}

Key words: tragedy, Euripides, The Phoenician Women, Jocasta, myth, audience.

\section{INTRODUÇÃO}

O prólogo da tragédia As Fenícias, de Eurípides, representada entre os anos 411 e 408 a. C, contém duas cenas: um monólogo (v. 1-87), proferido por Jocasta e a teicoscopia (vv. 88-201), cena em que um pedagogo e Antígona observam, de um terraço elevado do palácio que representa a skēne, a movimentação e preparação do exército argivo nos arredores das fortificações tebanas.

Quase todas as tragédias euripidianas começam com um monólogo seguido de um diálogo. Louis Méridier, estudioso de Eurípides, em uma citação de Amiech ${ }^{1}$, não tem simpatia pelos prólogos do poeta justamente por causa da presença de monólogos, os quais reputa de fastidiosos, excessivos e cheios de detalhes irrelevantes. De certo

\footnotetext{
${ }^{1}$ Amiech (2004:234)
} 
modo, Méridier reverbera a crítica antiga a respeito do estilo de composição poética de Eurípides, notadamente n'As Rãs de Aristófanes, representada em 405 a. C., quando o poeta cômico estabelece uma disputa entre Eurípides e Ésquilo, tendo Dioniso como arbitrador. O parâmetro avaliativo é a competência na arte dramática e os dois poetas vão, ponto por ponto, discutindo seus estilos.

Temos, então, o testemunho de um contemporâneo de Eurípides e de um leitor especializado na obra do dramaturgo grego. Não entendemos que Aristófanes tenha feito gratuitamente um ataque frontal ao estilo de Eurípides. Talvez tenha sido. Mas o que fica evidente é que os estilos derivam não só de escolhas pessoais, mas principalmente de uma mudança no modo de comunicação entre poeta e público por conta da cada vez mais crescente influência da escrita na época da composição d'As Fenícias². Voltaremos nesse ponto adiante. Por outro lado, quando Méridier faz suas ressalvas aos monólogos euripidianos, ele o faz de outra perspectiva: a de um leitor moderno. A nossa análise, portanto, parte da premissa de que o monólogo de Jocasta funciona como um instrumento poético no qual estão imbricados procedimentos convencionais importantes do gênero trágico antigo, tais como a escolha do mito, o modo como o monólogo em questão o abriga e, principalmente, como ele cumpre a função de provocar e sustentar na audiência ateniense do século V a. C. um estado de tensão dramática através da (re)visão euripidiana do mito dos Labdácidas. No entanto, precisamos lançar mão de uma breve discussão.

O festival das Dionísias Urbanas atraía um grande público ao teatro de Dioniso. Realizada anualmente, essa festividade tinha um caráter ao mesmo tempo religioso e político. Religioso por que era oficialmente uma liturgia a Dioniso, patrono do teatro, e consistia de procissões solenes, sacrifícios e concursos de poesia ditirâmbica e trágica; político por que cabia à cidade organizá-las e financiá-las ${ }^{3}$ - através dos seus agentes - e, por que havia o interesse dos atenienses pelo espetáculo artístico. Sommerstein sustenta que, embora nem todos os cidadãos tenham assistido às performances, «theatre audience (of about 15.000) must always have included a substancial proportion of the Athenian citizen body - probably never less than 20 per cent, and often as much 40 or $50 »^{4}$. Para se ter uma idéia de tamanho prestígio cívico, a assembléia reunia em torno de 6.000 cidadãos e os tribunais selecionavam seus jurados a partir de um plantel de também 6.000 cidadãos $^{5}$.

Como conseqüência do que foi exposto acima, a audiência conhecia muito bem os seus mitos de modo que possuíam na memória um vasto repertório de enredos. Isso só foi possível porque a tragédia consolidou-se como um veículo privilegiado do discurso poético, alcançando um prestígio cívico e artístico muito grande. Devemos ter em conta que a festividade das Dionísias Urbanas também era um contexto de disputa

\footnotetext{
${ }^{2}$ Havelock, no capítulo 12 de seu livro A revolução da escrita na Grécia (1994), trata dessa questão minuciosamente.

${ }^{3}$ Segundo Havelock (1994: 279), «um patrocínio civil tão marcado deve ter sido inspirado por algo mais que um mero amor pelo teatro. Seguramente refletia uma convicção de que o palco de algum modo desempenhava um serviço público vital. Isso faria sentido caso a tragédia fosse considerada como uma forma de educação, a ser fomentada com recursos públicos».

${ }^{4}$ Sommerstein $(2002: 5)$

${ }^{5}$ Goldhill (2001: 58)
} 
entre poetas: cada poeta, e três eram eleitos, apresentava uma trilogia seguida de um drama satírico. O poeta, então, foi impulsionado a buscar novas formas de manipulação dos mitos e do fazer poético.

Os prólogos de Eurípides, geralmente, começam com um monólogo caracterizado pelo detalhamento da ação e pela minúcia e franqueza com as quais ele informa a audiência sobre os caminhos a serem seguidos e o que tem acontecido até o momento em que a ação efetivamente começará. Para o leitor moderno da tragédia euripidiana esse modo de composição desnudaria as linhas centrais da ação trágica, pois o prólogo - mediante um monólogo - diz sucintamente e até certo ponto ${ }^{6} \mathrm{o}$ que irá acontecer. Mas a percepção da audiência é pautada pelo espetáculo cênico e pelas ações e falas dos personagens no espaço teatral. Portanto, o monólogo, dentre outras funções dramáticas, conecta a platéia no tempo e no espaço míticos.

Esse procedimento funciona muito bem quando, apesar de se tratar de mitos tradicionais e bem conhecidos da audiência, o poeta quer conduzir os respectivos eventos por outro caminho que não aquele já dramatizado por seus predecessores.

Vejamos, então, como o monólogo d'As Fenícias se encaixa perfeitamente nesse esquema, ora confirmando, ora surpreendendo a expectativa da audiência, mas sempre mantendo uma tensão dramática.

\section{MONÓLOGO, NARRATIVA DO MITO E AUDIÊNCIA N' AS FENÍCIAS}

Um ator, usando uma máscara de uma velha mulher, com os cabelos rasos e vestido com andrajos negros, expressando luto e pesar ${ }^{7}$, surge no palco, tendo saído do palácio, e profere um discurso mais ou menos endereçado à audiência, a qual não sabe se ela é uma servidora ou um membro da casa real. Esse discurso, de um tom bastante emocionado e retórico, é iniciado com uma breve invocação ao Sol (vv. 1-3). A indicação de Tebas como local da ação é feita no verso 4. Contudo, essa indicação é precedida do adjetivo dystychê, significando «infeliz», «inoportuno», aplicado ao substantivo que aparece no início do verso 5. Esse tipo de invocação, de acordo com Mastronarde ${ }^{8}$, de identificar a situação trágica, explorar as suas origens e endereçá-la a algum deus ou elemento, é uma convenção trágica. Por seu turno, Amiech sustenta que Jocasta toma o Sol como testemunha de sua cadeia de infortúnios 9 .

A indicação do local da ação, junto com o advérbio de tempo, somados à aparição do nome de Cadmo no verso 5, levam a audiência a deduzir que se trata, mais uma vez, da dramatização de um mito bastante conhecido - até porque o título da tragédia, de saída, apontaria para o território fenício -, mas não vislumbra qual é o grau de envolvimento da personagem Jocasta no referido evento infeliz.

\footnotetext{
${ }^{6}$ No caso da tragédia em questão, o alcance das informações passadas por Jocasta para a audiência vai até o primeiro episódio. Muitos outros episódios se desenvolvem após a cena do debate entre os irmãos, debate este antecipado por Jocasta no monólogo.

${ }^{7}$ Essas informações que caracterizam a personagem trágica só serão fornecidas ao leitor no primeiro episódio. A audiência, em contato visual, detinha as características da personagem logo de saída.

${ }^{8}$ Mastronarde (1994: 142).

${ }^{9}$ Amiech (2004: 238).
} 
Abandonando o tom lamentativo, a personagem constrói dois caminhos genealógicos para mostrar como a desgraça à que ela se referiu no verso 4 se instala paulatinamente em Tebas. Sua fala parte, primeiramente, de Cadmo, o ancestral fundador de Tebas, e descreve a sua sucessão de descendentes até culminar em Laio. Neste momento ela inicia o relato sobre a sua própria linhagem e a audiência toma conhecimento, então, de quem é que está ali, diante dela, como é mencionado nos versos 10-12.

Não se trata, então, de uma mera servidora do palácio, mas de uma figura importante no mito e conhecida do público ateniense. Até esse ponto, a audiência tem a informação quanto ao local da tragédia, mas não quanto ao tempo, isto é, em que momento desse mito a ação começará e quais eventos serão abordados. No verso 13 é lembrado o casamento de Jocasta e Laio. A julgar pelo enredo da tragédia $O$ Rei Édipo, de Sófocles, a audiência estaria preparada para ver uma dramatização cujos limites temporais foram estabelecidos por Jocasta e estão bem definidos: do casamento de Laio e Jocasta até a morte de ambos, apesar de a morte de Laio ser bem anterior. Nesse ínterim, muitas desgraças aconteceram e a audiência se localizaria e construiria a sua expectativa nessa faixa temporal. Mas essa expectativa não é confirmada, pois a narrativa começa a avançar, ainda no verso 13 , quando Jocasta detalha os eventos que se seguiram às suas núpcias com Laio.

Após um período de casamento, Laio incomodou-se com a ausência de descendentes ${ }^{10}$ e resolveu ir até o oráculo de Apolo para uma consulta. Numa animação interessante, Jocasta reporta a sentença oracular recorrendo ao discurso direto, nos versos 17-20. Além de ressaltar a função vívida do discurso direto no espetáculo cênico, como se o oráculo estivesse em cena, temos que considerar mais dois pontos, sempre na intersecção das tragédias Os Sete contra Tebas e O Rei Édipo, de Ésquilo e Sófocles, respectivamente.

Em Ésquilo (vv. 742-49), a predição oracular é reportada pelo coro e o seu conteúdo não menciona explicitamente o derramamento de sangue, mas condiciona a prosperidade tebana à ausência de descendentes de Laio. Em Sófocles, é a própria Jocasta que reporta a Édipo (vv. 711-14), quando ele já era Rei, que Laio recebera uma advertência segundo a qual a sua morte se daria pelas mãos de um herdeiro. O tema do sangue vertido, então, aparece em Eurípides e em Sófocles. Contudo, segundo Amiech ${ }^{11}$, a audácia do discurso direto só se encontra em Eurípides. O oráculo se manifesta diretamente para o público. Conseqüentemente, as marcas fortes da tragédia, como a hýbris, a hamartía, a áte e, sobretudo, a catárse terão outra forma de recepção.

Jocasta prossegue a narrativa dizendo que, não obstante a advertência oracular e numa certa ocasião ${ }^{12}$, Laio esqueceu-se das palavras do oráculo e fecundou o seu ventre (v. 22). A primeira falta trágica é, então, localizada nesse movimento de recuo temporal. Isto quer dizer que, apesar de não fazer parte da ação, a hamartía de Laio é

${ }^{10}$ Conforme Amiech (2004: 241), «a ausência de descendentes diretos, ou seja, uma linhagem masculina, era considerada uma maldição divina, e a ida ao oráculo para uma consulta sobre tal impedimento era um procedimento comum nas sociedades antigas.»

${ }^{11}$ Amiech (2004:242)

${ }^{12} \mathrm{~N}$ 'Os Sete contra Tebas (v. 750) o coro menciona que Laio cedera aos prazeres do amor. Aqui, Jocasta adiciona mais um: o frenesi de Baco. A paixão desenfreada e a bebida obscureceram a compreensão de Laio sobre o momento. A intervenção divina, personificada na Átē, levou Laio a cometer a falta. 
trazida à tona para ilustrar a ocasião da primeira catástrofe, geradora, inexoravelmente, das outras.

Mas quando reconheceu o seu erro (amplákema no lugar do termo técnico hamártema), Laio tentou, literalmente, pregar uma peça no destino: nascido o rebento, Laio perfurou seus tornozelos e ordenou que seus serviçais levassem a criança para longe e fixassem seus pés em algum local para que ela ficasse exposta à sorte (vv. 24-26). $\mathrm{O}$ menino recebeu o nome de Édipo ${ }^{13}$. No entanto, apiedados do garoto, pastores do rei Pólibo, de Corinto, que passavam pelo local, recolheram a criança e levaram-na para a rainha, que persuadiu Pólibo de que a criança fora gerada em seu ventre (vv. 28-31).

Essa passagem, que narra a tentativa de Laio - e registre-se, com a anuência de Jocasta - de se livrar do filho, se comparada à mesma passagem do Rei Édipo, fornece dessemelhanças importantes, sobretudo na caracterização de Jocasta. Por sua posição privilegiada de sobrevivente, a revisão dos fatos passados é, às vezes, acompanhada de dor, pois ela traz à tona a privação do prazer da nutrição de seu rebento, privilégio concedido a qualquer outra mulher. $\mathrm{O}$ sentimento da ausência de um prazer que ela poderia ter tido ainda a machuca, não somente pelo que ela disse textualmente, mas principalmente pelo que ela não disse. Tenhamos em conta que ela não nomeia a mulher de Polibo - Mérope - a quem seu filho foi entregue. Em Sófocles (vv. 717-19), Jocasta narra o mesmo fato com absoluta frieza. Há uma outra diferença de tratamento quanto ao mesmo evento: Pólibo, em Eurípides, crê que Édipo é seu filho, pois sua mulher o persuadira disto; em Sófocles, Pólibo sabe que a criança não é dele, pois lhe fora entregue por um servo.

Recorrendo a um salto temporal, Jocasta narra a passagem na qual o pai se encontra com o filho, quando Édipo parte de Corinto desejoso de conhecer sua verdadeira origem e Laio, por sua vez, parte de Tebas para consultar o oráculo a respeito do destino da criança outrora exposta à sorte. A simultaneidade de ações, movidas pelo desejo do conhecimento, resultou no encontro dos dois personagens na divisa da Fócida. Contudo, há uma diferença significativa entre a versão aqui apresentada da de Sófocles. No verso 779 e seguintes do Rei Édipo, o protagonista explica a Jocasta que fora até o oráculo para saber se a acusação proferida contra ele por um bêbado, segundo a qual ele era filho adotivo, era verdade. A sentença oracular previra coisas terríveis que seriam cometidas por Édipo. Confuso e errante, ele chegou até a encruzilhada, momento em que topou com a comitiva de Laio, o qual não se sabe se estava indo ou voltando de Delfos. N'As Fenícias, a audiência percebe que Édipo não foi a Delfos antes de se encontrar com a comitiva, ou seja, ele não consultou o oráculo e, assim, permaneceu na ignorância quanto à sua pergunta inicial até aquele momento. Admoestado pelo cocheiro de Laio e violentado pelos cavalos, Édipo levanta-se contra eles e mata o seu pai (v. 44) (sem saber que se trata de seu pai). Detalhe curioso é que a ênfase se dá na morte do pai, omitindo-se o destino do cocheiro. Mais curioso ainda é o acontecido imediatamente após a morte de Laio: Édipo pegou a carruagem real e a ofereceu, de

${ }^{13}$ É preciso notar que Édipo, no verso 77, é nomeado pela Grécia e não por seu pai ou sua mãe. Em seu monólogo, Jocasta explora o procedimento da nomeação. Segundo Craik (1988: 169), os antigos relacionavam o nome pessoal ao destino atual do indivíduo. Sófocles joga com as derivações do nome de Édipo. Sobre esse ponto, recomendamos a leitura do estudo de VIEIRA (2001) à sua tradução do Édipo Rei. 
presente, a Pólibo, seu «pai». Sobre esse ponto, Craik ${ }^{14}$ considera esse um «detalhe circunstancial e irrelevante», concluindo que Édipo «não poderia aparecer em Tebas com o espólio do saque», como se houvesse um lampejo de consideração da parte de Édipo. Discordamos nesse ponto porque o que está em jogo, aqui, é o éthos do herói e isso importa para a audiência, pois ela vê um Édipo diferente daquele que fora pintado, sobretudo por Sófocles. De acordo com Amiech ${ }^{15}$, «ele não se preocupou de maneira nenhuma de ter matado um homem que sabia ser rei, de modo que sua única preocupação foi presentear o seu pai com a carruagem». Ademais, Édipo estava indo para Delfos quando se encontrou com Laio, e não para Tebas. Por isso ele não poderia ter ido para essa cidade com a carruagem, como pensou Craik.

Com o trono de Tebas vago e a investida da Esfinge, cuja razão de aparecer nas cercanias de Tebas não é mencionada, Creonte, então, estabelece como recompensa a quem decifrasse os seus enigmas, o leito de Jocasta e o governo de Tebas (vv. 45-49). Chama a nossa atenção a maneira com que Jocasta introduz o episódio da decifração do enigma ${ }^{16}$, pois esse evento é essencial para o cumprimento de uma outra etapa nas desgraças de sua família, pois unirá mãe e filho num conluio catastrófico. Jocasta parece negar aquilo que ela mesma já havia identificado no início de seu monólogo, isto é, a ação de uma força sobre-humana no destino de Tebas e, por conseguinte, no destino de sua família. Apesar de inserir os acontecimentos funestos de sua linhagem numa conjuntura mais ampla, ao atribuir o sucesso de seu filho ao acaso, ela ignora que os deuses estavam por detrás do concurso das circunstâncias.

Com a vitória de Édipo, o cetro tebano, assim como Jocasta, foram parar em suas mãos. O resultado do incesto é descrito dessa maneira nos versos 55 a 58 :
«Gero filhos para o filho: dois machos,
Etéocles e a ilustre força de Polinices;
e duas donzelas: uma, Ismene, o pai nomeou; a outra, Antígona, primogênita, $\underline{\mathrm{eu}}^{17} . »$

Optamos por transcrever a passagem e seguir a ordem das palavras nos dois últimos versos do original grego para demonstrarmos que, contrariamente ao que $\mathrm{Craik}^{18}$ pensou, o alinhamento dos termos pai e mãe (eu) não é «um detalhe irrelevante introduzido puramente para um efeito antitético». Há questões claras aqui.

Em primeiro lugar, Jocasta demonstra que, apesar do incesto, havia uma aparente harmonia e igualdade na relação marido e esposa, pois Édipo nomeou Ismene e Jocasta teve a prerrogativa de nomear Antígona. Contudo, a nomeação dos filhos porta um desequilíbrio flagrante: Etéocles não possui nenhum ornamento, enquanto que Polinices acompanha a perífrase «ilustre força» e ocupa três quartos do verso grego. Além disso, o termo com o qual Polinices é designado (kleinēn) é uma adjetivo que integra o nome do irmão (eteós + kléos).

\footnotetext{
${ }^{14}$ Craik (1988: 171).

${ }^{15}$ Amiech (2004: 248).

${ }^{16}$ «Acontece de alguma maneira/ que meu filho Édipo aprendeu o canto da Esfinge» (v.49-50).

${ }^{17}$ Grifo nosso.

${ }^{18}$ Craik (1988: 171).
} 
Essa diferença de tratamento nos nomes pode ser interpretada como um tentativa de Jocasta de subverter qualquer antipatia da audiência pela figura de Polinices, a quem se relegou um papel secundário na dramatização d'Os Sete contra Tebas. Ressalte-se que o significado dos nomes concorre para a depreciação de um em relação ao outro: Polinices significa «muitas contendas» ao passo que Etéocles equivale a «glória verdadeira». O percurso narrativo aborda, até aqui, eventos centrais da lenda dos Labdácidas amplamente conhecidos do público que tivesse assistido às peças Laio e Édipo, de Ésquilo, e Édipo Rei, de Sófocles. Quanto às duas primeiras, repetimos, temos apenas suposições, já que nos restaram apenas fragmentos. Com exceção de um detalhe ou outro na interpretação dos eventos, a sua espinha dorsal permanece a mesma: Laio se casou com Jocasta e Édipo nasceu, o qual matou seu pai, casou com sua mãe e com ela teve quatro filhos. O ângulo temporal, que antes era maior na cobertura dos eventos e a partir do qual a audiência tentava deduzir a ação da tragédia As Fenícias, torna-se extremamente limitado, pois a audiência passa a ter como referência temporal, tomando por base as peças trágicas já apresentadas no palco ateniense, o suicídio de Jocasta e o auto-cegamento de Édipo após a descoberta do incesto e seus frutos. Após estes eventos não poderia mais haver ação que envolvesse a presença de Jocasta, pois, simplesmente, não mais existia Jocasta. A audiência, legitimamente, poderia questionar em que ponto do mito a ação que eles foram assistir começará efetivamente.

O que pode ter instigado a audiência é o confronto entre o que até então ela tinha visto ser dramatizado no teatro e a informação, mesmo visual, que se lhe apresentaria: uma Jocasta que mostra as marcas do tempo e as cicatrizes da dor, o que difere, certamente, daquela mulher que morrera na ocasião da descoberta do incesto na tragédia $O$ Rei Édipo, de Sófocles.

Contudo, a audiência sabia que a história da linhagem prosseguia com os filhos, pois assistira à dramatização d'Os Sete contra Tebas, de Ésquilo, em 467 a. C.. Mas, uma vez mais, nessa ocasião do conflito entre os dois irmãos, ambos, Jocasta e Édipo, estavam mortos. Sófocles, em seu Édipo em Colono, faz Édipo sobreviver até momentos antes do confronto entre Etéocles e Polinices, mas essa dramatização foi levada ao palco tempos depois da dramatização d'As Fenícias. Portanto, essa informação não pode ser um dado intertextual, segundo a perspectiva que aqui adotamos.

Os versos 59 a 62 da narrativa abrangem o momento em que Édipo descobre a sua situação $^{19}$, mas não menciona o processo, ainda que de relance, que o levou à anagnórisis. Os fatos seguintes, na peça de Sófocles, são o suicídio de Jocasta, declarado no verso 1235 e descrito minuciosamente nos versos 1236 e seguintes, e o auto-cegamento de Édipo, que perfura suas pupilas com os agrafos de ouro retirados das vestes de Jocasta (vv. 1268-69). É uma surpresa para audiência, portanto, a sobrevida (ou o renascimento) de Jocasta após a descoberta do incesto. Por outro lado, se prepondera para a audiência a informação de que o instrumento com o qual Édipo perfurou suas pupilas fora extraído das vestes de Jocasta, de onde veio o mesmo instrumento, nessa versão de Eurípides, já que Jocasta está no palco? Medda ${ }^{20}$ pensa que essa questão,

${ }^{19}$ N'As Fenícias, o verso 59 (mathôn t'amà léktra mētróiōn gámōn) corresponde aos versos 778-80 (epeÍ artíphron / egéneto méleos athliōn gámōn) d'Os Sete contra Tebas.

${ }^{20}$ Medda (2006: 122). 
provavelmente, não seria pertinente a um espectador antigo porque, como se trata de um agrafo de ouro, ele seria facilmente encontrado nas vestes de Édipo, visto que se trata de um rei. No entanto, como se trata de probabilidade, tendemos a pensar que a pergunta é, no mínimo, plausível e, por isso, merece ser sustentada.

No entanto, a audiência se perguntaria a respeito do destino de Édipo, pois, ele próprio, n'O Rei Édipo, sugeriu o exílio. Com o trono de Tebas vago, Creonte assumiu até a maioridade do primogênito. Mas Jocasta prossegue a narrativa com um salto temporal que chega na geração dos filhos, precisamente na maioridade de Etéocles e Polinices, quebrando, ainda que momentaneamente, a expectativa em torno do destino de Édipo. Ela reporta que os filhos trancafiaram o pai - mas não diz onde - para que a Fortuna se esquecesse das faltas cometidas por ele, numa manobra que lembra a tentativa de Laio de se desfazer do produto gerado após a desobediência ao oráculo.

A audiência poderia entender que, no lapso que compreende a cegueira de Édipo e o seu encerramento pelos filhos, o governo de Tebas teria ficado sob os auspícios de Creonte (ou que Édipo teria continuado no comando de Tebas até sua prisão. Essa segunda hipótese não é, de nenhum modo, inverossímil, dadas as alterações do mito feitas por Eurípides até então. Contudo, ainda permanece a pergunta sobre o destino de Édipo. Jocasta, então, anuncia, no verso 66, que Édipo continua vivo e está no palácio.

Esse anúncio deveria ter levado a audiência, no mínimo, ao espanto, e criado uma provável inquietação, já que o multi-sofredor Édipo poderia aparecer a qualquer momento do drama. Mas Jocasta, novamente, quebra a expectativa criada em torno de sua presença e inicia o tema da maldição de Édipo contra os filhos.

O que motivou Édipo a lançar a maldição, segundo a qual os filhos repartiriam a herança em um duelo de espada, pode ser entendido de duas formas, de acordo com a interpretação que se dá à expressão pròs tês týkhēs na metade do verso 66. Jocasta diz que Édipo estava mentalmente doente (nosôn) e que a origem está no significado daquela expressão, a qual pode ter um valor causal (adoecendo por causa do que the aconteceu, isto é, por causa do tratamento dos filhos) ou um valor de agente (adoecendo por causa da Fortuna). A primeira interpretação não exime os filhos de culpa enquanto que a segunda os exime, pois a insanidade do pai foi obra do Destino. Entretanto, é difícil imaginar que tipo de leitura a audiência poderia ter tido ou se essa distinção é por demais óbvia para ela. Qualquer que tenha sido ela, a visão de Jocasta sobre o termo da maldição é inequívoco: trata-se da mais ímpia (aràs anosiōtátas), isto é, uma maldição que extrapola os limites da lei divina. Nesse sentido, ela «toma parte e condena, em nome dos deuses, as imprecações lançadas por seu marido, o pai das crianças.» ${ }^{21}$

O temor de que a maldição se cumprisse se vivessem juntos levou os irmãos a adotarem uma estratégia emblemática na história da linhagem: a burla ao destino. Eles dispuseram, em comum acordo, que o mais novo (Polinices) deixaria Tebas voluntariamente, enquanto que o mais velho (Etéocles) reinaria por um ano, ao término do qual deveria transmitir a Polinices o governo da cidade, num sistema de alternância. Quando findou o primeiro ano, Etéocles descumpriu o acordo e, além disso, expulsou o irmão de Tebas. Ressalte-se que o exílio voluntário e o sistema de alternância no

${ }^{21}$ Amiech (2004: 255). 
comando da cidade não figuram n'Os Sete contra Tebas. Na tragédia de Ésquilo, nos versos 637-38, alude-se somente à expulsão de Polinices.

Exilado em Argos, Polinices tornou-se genro de Adrasto e consegue a sua promessa de reunir um exército para retornar a Tebas e exigir do irmão o cumprimento do acordo. Jocasta, em As Fenícias ressalta que o filho quer apenas a parte que lhe é devida e não o todo. Assim, ela estaria reprovando a ambição de Etéocles e sublinhando a sensatez de Polinices. Na esteira da nomeação dos filhos, ela estaria preparando a audiência para a entrada em cena de uma figura diferente daquela retratada no drama de Ésquilo e por quem a audiência não teria muita simpatia.

Etéocles descumpriu o acordo, não repassando o poder ao irmão. Além disso, expulsou Polinices de Tebas. Exilado em Argos, Polinices recebeu o apoio de Adrasto, rei da cidade, para reunir um exército e marchar até Tebas para recuperar seus direitos (vv. 69-78).

A chegada de Polinices, diante das fortificações Tebanas, para travar uma disputa com seu irmão pela parte da herança paterna, encaminha o monólogo para o seu fím. Além disso, trata-se do ponto de partida do drama que a audiência assistirá. Como esse também foi um evento dramatizado e ela sabe de seu desfecho na tragédia de Ésquilo, ou seja, que os irmãos morrem duelando, além de saber que naquela perspectiva trágica Édipo e Jocasta estavam mortos, o público se perguntaria, certamente, a respeito dos papéis que serão desempenhados tanto por Édipo, quanto por Jocasta nesse contexto de disputa até então enunciado. Vai além: seriam eles capazes de dissolver o conflito de modo que o seu desfecho fosse outro que não aquele desfecho d'Os Sete contra Tebas? Da parte de Jocasta, a audiência toma conhecimento de sua função: mediar um diálogo entre Etéocles e Polinices com vistas a uma solução pacífica. E o mensageiro enviado por ela até o front dos argivos disse que ele virá. A expectativa da audiência se concentra, então, na entrada em cena de um personagem que foi relegado a um papel marginal e até inglório, pois na tragédia Os Sete contra Tebas, o foco da ação está em Etéocles; Polinices não figura entre os personagens do drama e, por isso, não tem voz. As suas intenções são reportadas por um mensageiro: ele quer lutar com seu irmão até a morte ou impor a seu desafeto o exílio. Sendo um dos personagens do drama euripidiano, a audiência certamente poderá ouvir dele uma outra perspectiva dos acontecimentos.

\section{CONSIDERAÇÕES FINAIS}

Durante todo o percurso narrativo do monólogo, Jocasta entrelaça o enredo das tragédias $O$ Rei Édipo, de Sófocles, entre os versos 13 a 62, e d'Os Sete contra Tebas, de Ésquilo, entre os versos 63 a 80. A revisão do mito dos Labdácidas, embora feita de forma sucinta, não deixa de envolver a audiência numa atmosfera de tensão dramática. Eurípides retarda a definição do tempo trágico adotando a estratégia do recuo à origem dos infortúnios dos Labdácidas, mostrando como as desgraças se instalaram através de eventos específicos. Tais eventos, sobretudo os matrimônios de Laio e Jocasta (v.13), de Édipo e Jocasta (v.53) e de Polinices e a filha de Adrasto (v.77) decorrentes da áte, que cegaria os homens, impedindo-lhes que tivessem discernimento em um dado instante, tornaram-se os veículos de perpetuação do mal, isto é, do infortúnio, ou 
atûchēma, que é o mal causado de modo imprevisível. O último evento possibilitou que os acontecimentos culminassem na situação inicial do drama: a luta entre Etéocles e Polinices, como resultado da maldição de Édipo, e desencadeada pela recusa do primeiro em ceder o trono ao segundo, conformemente ao pacto contraído entre eles para escaparem, exatamente, daquela maldição.

Longe de ser um monólogo digressivo e recheado de detalhes irrelevantes, tentamos demonstrar, ao longo deste trabalho, que tais detalhes servem como contraponto para a audiência, fazendo com que ela projete a sua expectativa com base no entendimento daqueles mesmos detalhes. Por isso, a recapitulação de elementos conhecidos do mito dos Labdácidas, associados a novos elementos, provê a audiência de informações importantes, sem as quais ela estaria insuficientemente preparada para compreender o momento de partida do drama, o desencadeamento das ações e a relação dos personagens nos episódios da tragédia.

Devemos voltar ao ponto em que falamos da mudança paulatina que a poesia oral sofreu com a infiltração cada vez mais crescente da escrita na Atenas do fim do século V a. C. De acordo com Havelock:

O fato de que, de qualquer modo, a informação é requerida, indica a presença de certas necessidades do público, as quais estavam a ser modificadas no tempo que Eurípides escreveu. Não havia programas de teatro para consultar (ou teriam eles, quem sabe, aparecido justamente na época de As rãs?). Há muito já se observou que o prólogo falado de certo modo ocupa o lugar de tais programas. Aceitando-se o pressuposto de que o drama convidava o público a identificar-se com a ação, podemos considerar que o prólogo nos diz onde estamos, quem somos, o que aconteceu ou foi feito no passado, e o que está em vias de acontecer, ou ser feito, no presente, para reagir de modo apropriado no passado. ${ }^{22}$

Essa forma de enunciado informativo característico do monólogo euripidiano está inserida num contexto mais amplo e que chamamos de cultura oral, quer dizer, a disposição das informações com clareza e objetividade concorre para uma melhor percepção auditiva dos espectadores e estabelecem uma experiência emocional e intelectual mais ampla. Além do mais, tal dispositivo informativo funciona muito bem quando, apesar de se tratarem de mitos tradicionais e bem conhecidos da audiência, o poeta quer conduzir algumas ações por outro caminho que não aquele já percorrido por seus predecessores.

Merece destaque, sem sombra de dúvida, a sobrevida de Jocasta por um tempo muito além da descoberta do incesto. Sobretudo, porque a personagem que esteve no epicentro de todas as desgraças, envolvida numa série de catástrofes, agora tem a oportunidade de mostrar a sua versão, ou melhor, sua visão do acontecido. Mesclando sobriedade com dor, a sua narrativa, inevitavelmente, coloca a audiência diante do patético, pois Jocasta tem diante de si um esquema de inevitável destruição, uma catástrofe de proporções, de certo modo, previsíveis e que ela tentará evitar. E, apesar da aparente liberdade e responsabilidade, ao encerrar seu monólogo, ela dirige uma breve invocação a Zeus, deixando entrever que a sua arbitração, em cujo sucesso se deposita a esperança de salvação de sua família, só será possível se Zeus assim o permitir.

${ }^{22}$ Havelock (1994: 305-06) 


\section{REFERÊNCIAS BIBLIOGRÁFICAS}

Amiech, Christine (2004), Les Phéniciennes d'Euripide. Paris.

Burian, Peter (1997), «Myth into Muthos: the shaping of tragic plot» en Paul Easterling (ed.),

The Cambridge Companion to Greek Tragedy, Cambridge:178-208.

Craik, Elizabeth (1988), Euripides: Phoenician Women. Warminster.

Croally, Neil (2005), «Tragedy's Teaching» en Justina Gregory (ed.), A Companion to Greek Tragedy, Oxford: 55-70.

Goldhill, S. (2001), Reading Greek Tragedy. Cambridge.

Halleran, Michael R. (2005), «Tragedy in Performance» en Rebecca Bushnell (ed.), A Companion to Tragedy, Oxford: 198-214.

Havelock, E. (1994), A revolução da escrita na Grécia. São Paulo.

Mastronarde, Donald (1994), Phoenissae. Cambridge.

Medda, Enrico (2006), Euripide: Le Fenice. Milano.

Sommerstein, A. H. (2002), Greek drama and dramatists. London. 